\title{
PALABRA Y UNIVERSO EN LA ESCRITURA DE ARMANDO ROMERO
}

\author{
POR \\ EDUARDO ESPINA \\ Texas A\&M University
}

Mas allá del desafió a la razón y de la ruptura con la causalidad que se advierte explícitamente en una primera lectura, las características fundantes de la obra de Armando Romero son difíciles de encasillar en un macrotexto delimitable que la defina en su organicidad, sobre todo teniendo en cuenta que las distinciones genéricas son absueltas y los desvíos enunciativos dejan de participar lógicamente en un proceso de significación o de producción de sentido. Los textos de Romero (Cali, 1944), como aquéllos de Henri Michaux y Max Jacob, transpasan el territorio de las fáciles clasificaciones para convertirse en su origen: sola escritura ${ }^{2}$. Dadas las circunstancias de esta aventura escrituraria, vano será entonces delimitar la autonomía de un cuento o de un poema como género específico, cuando los signos, más que conformar categorías temática y estructuralmente identificables, que podrían indicar las señas de identidad de lo expresado, se refugian en su blindada intimidad para no ser más de lo que dicen. Recuerda al respecto Noe Jitrik que la idea de los géneros ha perdido la vigencia que tenía en un pasado cercano: "La distinción no es trivial: significa que se sigue escribiendo poesía o novela pero ya no se piensa en el cumplimiento de requisitos que otorgarian una identidad de género" ${ }^{\text {. }}$.

Punto de partida: se hablará de una escritura Romero, pues la invención, ya a la manera de prosa o de poema, es un acto de productividad: un producto que no termina nunca de acabarse. Textualidad indefinida. ¿Poemas en prosa o cuentos verticales? Al otro lado de la indefinición que resiste el encuentro de una verdad única y axial, resalta la prevalencia de una voz; lírica antes que

1 La obra de Armando Romero incluye: El demonio y su mano. Caracas: Monte Avila,1975; Los móviles del sueño. Merida: Ediciones de la Gobernación del Estado, $1976 ;$ El poeta de vidrio . Caracas: Fundarte, $1979 ;$ La casa de los vespertilios. Caracas: Monte Avila, 1982; Del aire a la mano. Bogotá: ABC y Colcultura, 1983; Las palabras están en situación. Bogotá: Procultura, 1985; El Nadatsmo o la búsqueda de una vanguardia perdida. Bogotá: Tercer Mundo, 1988; Gente de pluma. Madrid: Orígenes, 1988) y Las combinaciones debidas. Buenos Aires: Ultimo Reino, 1989.

${ }^{2}$ Noe Jitrik, La vibración del presente. México: Fondo de Cultura Económica, 1987, p. 142. 
anecdótica: la escritura no trae historias, apenas palabras tratando de salir a la superficie a mostrar sus rostros maquillados. El signo es autotélico. Se cumple la profecía de Mallarmé: el placer del poeta estará únicamente en la inquietante tarea de escribir. Integrante del movimiento nadaísta que tuvo su actuación en Colombia entre 1958 y 1972 y al cual dedica uno de los ensayos comprensivos más lúcidos realizados hasta el presente, Armando Romero, por más que se distancia de su marco referente, prolonga la insatisfacción nadaísta en cuanto el texto busca una expresión imposible; una escritura fuera de la literatura, una lírica que no sea el mundo, sino su invención definitiva; una creación a imagen y semejanza del lenguaje $\mathrm{e}^{3}$. Precisamente dicho sostenimiento de la imagen como gesto total de lo fenoménico y como única materia sensible de la realidad, conforma la matriz caracterizante de una poética donde las palabras son el punto de partida de todas las cosas. La estrategia para consolidar ese apropiarse del universo conoce ciertas coincidencias formales que son distintivas: condensación acumulativa que no conduce a un conocimiento del objeto o sujeto enunciado sino a su dispersión: "las espirales nos conducen por un dulce día/los pájaros se levantan a masticar sus barrotes/la hormiga crece como mi indiferencia"; colmada abundancia de enumeraciones, por momentos de elucidación caótica, marcada por series de frases subordinadas o sintagmas aislados que confluyen en un final de texto, tan elíptico como categórico: "Del hechizo el ahora y lo inmediato/Dos cuerpos que desaparecen de amor en el espacio/Es destino la materia que lentamente se disuelve"; muchos de los textos son derivativos de situaciones contingentes a través de las cuales el encadenamiento lógico del mundo empírico es revertido, hecho absurdo: "El paraíso de su carne/Con la cabeza a pájaros/Ruedo por el mundo"; posposición de un elemento unificador, temático o conceptual, en cuanto la escritura evita todo centro de figuración o resolución de las contradicciones del poema: "El péndulo flota suspendiendo una línea de olvido a resurrección/Altas montañas de siempre/Dad paso a los ojos de miércoles".

¿Hacia dónde va el texto y qué contiene? Una de las respuestas: el mundo como imagen y representación. La propuesta se cumple mediante una escritura que se insubordina al orden lineal de su recorrido, originando un progreso emotivo, imaginistico o fortuito que termina en una ausencia, en un vacio de

${ }^{3}$ El poeta Gonzalo Arango, redactor del primer Manifiesto Nadatsta, afirma: "El ejercicio poético carece de función social o moralizadora. Es un acto que se agota en sí mismo, el más inútil del espíritu creador. La poesía es, en esencia, una aspiración de belleza solitaria. El más corruptor vicio onanista del espíritu moderno".

${ }^{4}$ Las citas provienen de los libros Del aire a la mano y Las combinaciones debidas, posiblemente donde se concentran los mejores logros de Romero. Evito la numeración para motivar una lectura total de la lírica de este poeta colombiano y para cumplir también con la propuesta nadaísta que afirma que "Todo lo que está consagrado como adorable por el orden imperante será examinado y revisado". El posible orden corre por cuenta del lector. 
sentido, o bien a través de una abstractiva recurrencia al aislamiento lingüístico como único escenario de las formas. Es el triunfo de la letra, que descubre lo impresentable; lo indecible: la escritura figura una utópica permanencia: hay algo que se concibe, aunque no racionalmente, cuya viabilidad no depende de una supresión totalizante de los espacios del lenguaje que se niegan a la empatía o a la experiencia de lo conocido. Partiendo de un gesto de alumbramiento del idioma ("Hay algo que canta/Que no es el silencio"), la escritura de Romero asume una conciencia de sí que le permite acceder a la extremidad de un movimiento diferente y explorar todo aspecto de la realidad que sea contradictorio o no integrable. Aunque el material retórico permite localizar un mundo de carne, de cosas y de sílabas adyacente a la escuela surrealista ("Hoy amanece/ Diez y agosto/André Bretón ha dicho pasa"), el resultado final destaca una experiencia de rigurosa lucidez donde el universo, más que dividido y dinamitado como podría estarlo en una práctica delirante, aparece minuciosamente comprendido. Sin embargo, la desmesura se instala en lo real no por un abandono del orden, sino por un exceso de éste: "Se funda el desorden un día cualquiera/De otro orden deshilan auroras sangrientas". El lenguaje anticipa la experiencia del límite; el sujeto, tanto ideológica como corporalmente esta fragmentado: "y digo de la vida que sí también, que me/tomo su sopa amarga, que la vomito sobre/todas las piernas de la belleza". Las distintas zonas de violación del discurso sirven para destacar el desencanto y la existencia apócrifa que sobrevive la palabra sin otro azoro que ella misma, saliendo y regresando a su sino. En su soledad cósmica, el poeta se refugia en las sombras del alfabeto; sin nada, apenas le queda la invención del lenguaje: ponerle los nombres al mundo para descubrirlo. Es el poeta de la posmodernidad; no produce un trabajo gobernado por reglas o normas preestablecidas: las reglas es lo que busca al dar cabida a la existencia de un texto. Ante el desarraigo dado por la inconsistencia del acontecer de todos los días (la rutina, la historia como repetición), el poeta no encuentra otra isla de apoyo que el propio lenguaje: refugio del condenado donde trata de "atrapar el movimiento"s.

En la poética de Romero la fugacidad se hace letra; ésta hace de su expresión la permanencia del instante. La advertencia de Octavio Paz encuentra aquí su verificación: "El poema traza una raya que separa al instante privilegiado de la corriente temporal ${ }^{\text {n. }}$. La trascendencia estará en lo inmediato; "Porque en su horizonte perdura este ahora/De donde esta lucha que lo integra/No es paz sobre la hierba": el signo que escribiéndose se niega para poder seguir existiendo en un horizonte de futuro y novedad. La limitada posibilidad de la razón o la

\footnotetext{
${ }^{5}$ Para entender más la personalidad del poeta, recomiendo la entrevista con Romero que mantuvo el crítico peruano Miguel Angel Zapata, publicada en el libro Coloquios del oficio mayor . Providence: Inti, 1989, donde distintos temas relacionados con la tarea lírica son tratados.

${ }^{6}$ Octavio Paz, El arco y la lira. México: Fondo de Cultura Económica, 1986, p. 186.
} 
infinita imposibilidad del conocimiento humano en tanto proceso lógico y concluyente capaz de resolver el enigma esencial de todo, colocan al poeta ante la disyuntiva de negar la actualidad dada: "Todo objeto está al borde de la magia: hay/que empujarlo. Sube o asciende: hay que/empujarlo". Pero ese devenir en el instante hacia las formas del apocalipsis se consigue de manera celebratoria; el aterrador sentido del fin y del vacío provoca una situación vertiginosa tras la cual despunta una voluntad de asombro por lo inacabado del universo: "Que amamos más de lo que estamos amando/Sin control ni acierto/ ¡Oh mundo!” La continuidad del mundo, situada entre la extinción y la pervivencia, se establece en el texto de manera metonímica; como lenguaje que al excederse llena las ausencias de lo real. La incertidumbre se hace serie ininterrumpida, simulacro de la continuidad. Como en casi toda estética de posmodernidad, aquí también la metonimia prevalece; la metáfora estaría sustituyendo algo, pero ese algo (como máscara de una representación desviante) en verdad no existe y por lo tanto no puede ser sustituido: se inventa en la propia cadena enumerativa. La escritura de Romero privilegia el signo, pero no como problema resuelto; en todo caso como misterio para ser habitado. Además, la imagen busca su autonomía libre del peso de la metáfora, la cual puede ser traducida. Otra vez la figura se descentra; infija sale a la periferia, tiene silueta helicoidal: "A la furia/No es un sueño lo que estoy enviando/Es tal vez la relación de un viaje por mi geografía imprevista".

La escritura se fuga; es imposible de aprehender pues el río de la imaginación toca todas las orillas sin detenerse en ninguna. La palabra tiende a la transgresión; la representación del signo será como significante que ha perdido el significado: "Cuesta poblar o vaciar el saco/Fiel a tantos murmullos sin secreto/A tal límite sin fronteras". Enumeración antagónica de realidades que lejos de enfrentarse se hacen simultáneas en su fragmentación. Pero en tal fragmentación se filtra un deseo de totalidad; surge un espacio continuable donde desaparecen los vacíos de conocimiento que el sujeto tiene de la realidad: la desmesura del contemplador hará del objeto contemplado parte del ser del contemplante: "A meterse entre los ojos dicen/y ya son caballo inmóvil sobre el desierto/mirada fija en el círculo del valle". La muda aparición del lenguaje en el mundo, en cuanto la letra habla para adentro y exige un profundizar en su decir, asegura la inefable multiplicidad de lo real que consigue expresarse incluso en su silencio. La realidad piensa distinto de lo que es; se manifiesta como alteridad y como "un afuera a su propio ser".

Pero no es lo único: la poética de Romero exhibe además un travestismo escritural que admite la poetización total de las trivialidades del mundo inmediato para ampliar las posibilidades expresivas del idioma a través de una reclusividad y profusión de la imagen como instrumento indagatorio de los límites más inaccesibles del texto y del mundo que lo escribe: "Ninguna cortina/ Sólo una cara enorme pintada con ojos". La imagen no cuenta, ve. Por eso la 
escritura reconoce como nudo de la poética a una fenomenología del ver del ojo como lugar de partida del conocimiento. Una mirada que ve, que se ve y que es vista: "Por fin me veo/Esta noche de diciembre/Tejiendo el mundo/Con un par de ojos suel tos". La mirada, asimismo, prolonga su poderío para venir a ser nexo de unión entre la imaginación y la memoria: "Todavía ayer mi mano no podía levantar los temblores/El arado descansaba sobre cestos de basura/Imaginaba mi piel vistiendo un par de ojos fijos". Imagen y lenguaje sostienen la misma ilusión cognoscente. Ilusión, eso sí, pues la articulación de lo iconográfico con lo verbal promueve un abanico de visiones y significancias (el sentido está abandonado al arbitrario acopio de gozo textual) cuya figura arborescente caracteriza el despedazamiento de la unidad y de las correspondencias: "Era tanto como pájard/O mejor que alondra/Era lámpara y baúl”. Sin principio ni fin (ni tampoco finalidad), la pluralidad teleológica del signo sitúa la lírica en un violento ritmo de indefinición. Se verifica un corte, una escisión en el trayecto estructural de los textos, producto no de otra cosa que de la alianza de un lenguaje que quiere ser imagen y de imágenes que sólo pueden expresarse como silenciosas letras de un alfabeto visual: "Es que soy así como la imagen me rescata/Noche a noche/En los móviles del sueño". Hacia allí, hacia un inconsciente iluminado, se dirige la traza escrituraria. De todas maneras, la arborescencia, ayudada por las series enumerativas, permite individualizar islas de sentido cuya información es mínima, gestual casi, y contenida en un ritmo interiorizado que no se desplaza más allá de su propia pulsión. La fuerza implosiva es notoria; el texto se atomiza y cada parte tiende a la internalidad y a la autocomplacencia. Esas islas de representatividad son los lugares donde el discurso reconoce lo indivisible de su totalidad en los fragmentos de ésta. La realidad, por lo tanto, al ser disuelta, no es anulada, más bien problematizada por las varias insistencias de multiplicidad que caracterizan el sospechoso orden unitario: "Fue sólo un múltiple movimiento de pies/Pero al detenerse el limonero/Todo en aquel sitio continuó como antes”.

En la lírica de Romero la contradicción establece su legitimidad; en la fenomenología de la imagen descansa la justificación del acto de ver. El ojo, como cámara fotográfica del inconsciente (y como la propia poesía), tiende a la síntesis. A una dudosa síntesis de las apariencias del universo: "Ojos que de restar inquietos al objeto se someten/Y desde allá exigen salvar las dudas y el tormento". El ojo de la palabra intuye una simultaneidad en la piel del universo, pero la misma será en definitiva utópica ya que la proliferante escenografía de lo contingente corroe la condición integradora de la mirada y la hace ajena a su mismo actuar. De todas maneras, la escritura se hace visión de su verbo: "Hay imágenes/Van hasta el museo/Se coleccionan a sí mismas". La página es el vaciadero, más bien el museo de las imágenes que el ojo ha rescatado como sustancias de lo maravilloso, de lo que no puede ser dicho de otra manera. Así pues, el translado epistemológico de una materia reconocida (el universo como 
ámbito de incertidumbres) a otra que recién comienza (la página como espacio de aclaración de certezas) tiene una resultante radical; lo cotidiano, aquello dado por muestra de evidencia, en el transcurso de su traducción a la escritura pierde la legitimidad del origen y termina siendo una novedad absoluta: "A] sacar la cabeza más allá de los ojos pudo contemplar/Al sacar el cuerpo entero todo fue distinto: de ruinas se/lenaba el espacio y en lugar de resolana había una cenagosa confusión nutrida por la lluvia". La página exhuma las interrogantes de un espacio de representación que sólo puede ser satisfecho por una novedad absoluta y tal vez imposible. La escritura, por lo tanto, no trata de descifrar la verdad del universo, sino de continuar indagando en las apariencias de sus difíciles misterios: "Debajo de estos párpados que ya recuerdo en exilio/ Comienza a insinuarse la luz de una frontera adversa/Así el ver se interna en sus contrarios".

En la lírica de Romero la imagen se mira en el espejo de la existencia. La figura devuelta será irreconocible, pues el ojo escribe no de lo que ve, sino de lo que no puede ser visto: "Así, vio que saltaba de la oscuridad creciente/el último vislumbre: relámpago de otros ojos que desde/el fondo lo invitaban al olvido". La realidad representada es la que niega la posibilidad de representación, la que escapa del signo. Por eso la intermitencia metonímica es palimpséstica; los secretos nuncan terminan de revelarse: "Del concierto de vacuos elementos/Así se logra de lo escondido objeto/Para plegar la noche en la palabra”. Las islas se suceden; la vibración del lenguaje es acumulatoria y continua, lográndose una ruptura entre la realidad y lo real, un abandono solipsista del texto a su único, intransferible acontecer. Dice Alvaro Mutis que encuentra en la poesía de Romero "un mundo que le es esencial y sólo compartible a través de la delgada rendija de sus poemas"7. En todo caso, los textos de Romero no llevan a ninguna parte más allá de su propio Ser. Como el héroe griego que después de recorrer grandes distancias llega al mismo lugar, dándose cuenta que la travesía sólo ha sido dentro suyo, de igual manera estos textos son viajes dentro de sí mismos: un interior por donde toda la realidad ya ha pasado y que hace del acto de la contemplación un oficio oracular. Los ojos ven para adentro: "Y alguien muy interno e invisible desde dentro/Pestañea en orgullosa interrogación”. El sentido apropiado por la escritura desde el lugar de la enunciación que lo propicia destaca una voluntad de fuga hacia un espacio fuera de los límites de la belleza. Se trata de un "narcisismo cósmico"; el drama del poeta y el drama del universo se igualan en idéntica sustancia hechizada ${ }^{8}$. El poeta rescata la mejor acepción de su nombre: "Así construí el mundo que podía recorrer/de un sólo paso, acariciar con la mirada desde mi cuarto./Así pude vencer el estremecimiento".

\footnotetext{
${ }^{7}$ Alvaro Mutis en la nota introductoria del libro Del aire a la mano, p. 14.

${ }^{8}$ Gastón Bachelard, El agua y los sueños. México: Fondo de Cultura Económica, 1978, p. 71.
} 
La imagen del mundo es atravesada; los ojos de la escritura ven ahora el mundo desde dentro de él; dentro de su materia y de sus sueños: "Hay en su mirada/Mucho cielo/Mucha planta". En las palabras se materializa lo imaginario. El poeta no sólo es un explorador de sí mismo, sino que además se interna en la vida onírica de las cosas, ordenando los restos de un mundo que resiste la ausencia de lo visual y que se muestra en aquellos fragmentos de lo maravilloso donde las cosas hablan como nombres en una concurrencia fascinante donde la realidad es y no es al mismo tiempo: "Las figuras que surgen/Crean y destruyen/ Nunca se encuentra dos veces la misma forma". El mundo sueña y la escritura es la consecuencia de su despertar. Es la reinvención mítica de una palabra que optimista protagoniza la desnudez esencial del pensamiento y de todas las cosas; cogito del soñador insomne que a diferencia del cogito del pensador no separa el espíritu de los objetos; los hace partícipes de igual aventura a través del sueño. Así, la experiencia sensible del poeta asume el sentimiento de las cosas: "El pararrayo ruge como un salmón/El desierto brinca como un potro gordo y/sedoso". El poema disuelve el estado de tensión incluido en el mundo material por la incomprensión padecida por las cosas y recupera la quietud transparente de sus apariencias. En este abordamiento, en esta posesión doméstica de lo visible, las imágenes del mundo son poseídas inmediatamente: dejan de ser secretas para acceder a la misma cuota de felicidad . El "narcisimo cósmico" hace de la lírica la más hermosa mesa de disección. El universo es abierto y en su jardín de vivencias se siente una intimidad acechante; es el encuentro perfecto entre la voz del universo y el oscuro fondo de su mensaje que origina la satisfacción del descubrimiento: "Lograr que de tu ciudad de hierro surjan/las imágenes de un mar maravillado por/los espejos". Instante de restituida trascendencia cuando el invisible cuerpo del mundo se desnuda y se consolida la abolición de la dialéctica del sujeto y del objeto; el drama ancestral se resuelve: el mundo estará hecho con la misma sustancia que el ser. El pensamiento y las cosas dejan de resistirse mutuamente: "Sus formas muerden al mundo para sembrarlo/y lo cargan del placer de las imágenes/al ser pájaros en el nudo de la planta". La herida epistemológica se cierra; el universo del poema es la suma de todos los universos. La historia se realiza otra vez, pero en una página: el Verbo es anterior al universo y lo contiene. Conclusiones: la poética de Armando Romero, como texto, asume la afectividad de las cosas; mundo y palabra se identifican. La materia y lo trascendente se confunden en una catarsis radical. La página es la caja de resonancia donde se celebra el matrimonio, no sólo entre el cielo y el purgatorio, sino además entre la vida de las cosas y la de sus contemplador. El enigmático murmullo de la palabra refleja el instante mágico cuando el pensamiento y lo pensado alcanzan la unión. La materia imagina, lo imaginario toma formas. La eclosión imaginaria va en dirección del objeto hasta formar parte de éste y hacerlo palabra: la imagen de las cosas es la imaginación de éstas. Entonces, la mirada poética es escandalosa: 
despierta el furor de los contrarios y hace del sujeto imaginado y del ser imaginante el mismo signo, la misma cantidad de complacencia y conocimiento. Esta lírica pone al universo en un estado de autorreflexión; las cosas atraviesan una catarsis de afectividad: sueñan sus formas y padecen su ser. En la escritura, por lo tanto, más que una experiencia de la realidad hay un verdadero sicoanálisis de ésta, expresándose como matriz de un lenguaje redentorio. En su anónima pasividad, el mundo es por fin obligado a pensar por sí mismo, a expresarse desde su soledad, a sentir en la lucidez de su sueño al sujeto que inventa el fascinar de una escritura interrogante.

El lenguaje se excede y hace surgir la irrefutabilidad de lo imposible; las palabras se adelantan al sentido. Es la desmesura de los nombres - soñándose y despertando en el sueño de otro-que desestabiliza el equilibrio de las páginas del universo, para hacer de ellas y de su fascinación, un escenario conflictivo, un teatro de probabilidades donde lo real y su alteridad devienen parodia y encantamiento. Hay una subversión irreverente y festiva del mundo. Las palabras se disfrazan de sí mismas y al contemplarse se sorprenden. El espacio lírico rompe con las semejanzas, incluso las suyas propias, para afirmarse con gozoso impudor en las playas de lo nuevo. Su mar tiene tres orillas y es en la tercera donde desembarca la flota de los nombres: en el agua de lo no visto, en la luminosa materia de lo invisible. La palabra "Convierte imagen de mariposa/ En polvo simple o sortilegio", negando su anterior sincrónica rutina de repeticiones: apuesta al juego de su dificultad. Es el Verbo del comienzo, del primer origen, cuando al mundo -enorme página en blanco- había que nombrarlo antes que crearlo. $Y$ en ese definitivo nombramiento descansa la entrópica consistencia del riesgo y la originalidad de la escritura de Romero: las voces del lenguaje consagran el más exacto ámbito, donde las palabras y las cosas son lo mismo, pues aquí el Universo es apenas la imagen ficticia del Univerbo. 